\section{Daylength, Cold Storage, and Plant- production Method Influence Growth and Flowering of Asclepias tuberosa}

\author{
Mary Lewnes Albrecht and Jerald T. Lehmann \\ Department of Horticulture, Kansas State University, Manhattan, \\ KS 66506-4002
}

Additional index words. butterfly flower, florist crops, herbaceous perennials

\begin{abstract}
Greenhouse- and field-produced plants of Asclepias tuberosa L., butterfly flower, were forced in the greenhouse under various daylengths to produce flowering plants for the florist industry. Examined were post-production cold storage temperature (4.5 and 10C) and period (12, 14, and 16 weeks), forcing daylength $(9,13,15$, or 17 hours), plant-production scheme (greenhouse- vs. field-produced), and planting depth (exposed crowns or crowns planted $1.3 \mathrm{~cm}$ below the medium surface). When forced under a 9-hour daylength, blind shoots and aborted flower buds were prevalent. When daylengths exceeded 13 hours, using night interruption, the time to produce a marketable plant was reduced from 71 days to 61 days for 18-month-old greenhouseproduced plants. Daylength of 17 hours delayed flowering of field-produced liners by 15 days in comparison to those forced under 13-hour daylength. Greenhouse-produced plants stored at $10 \mathrm{C}$ did not sprout when brought into the forcing greenhouse held at 17/25C (night/day). Field-produced plants, when greenhouse-forced, had fewer flowers per inflorescence ( 88 to 94 flowers) than greenhouse-produced plants (79 to 87 flowers).
\end{abstract} looking for new plant material that can offer the consumer multiple uses, such as for the interior environment and in the landscape. At present, few traditional florist crops offer this dual use because most lack winter hardiness. New crops also need to offer something different in color, form, texture, and keeping quality. Butterfly flower has potential for potted florist crop production since individual flowers have an average life span of 7 to 8 days in native settings (Wyatt, 1981), with multiple flowers per inflorescence and multiple inflorescences per plant. It is selfincompatible for pollination (Wyatt, 1981) and has limitations on fruit set and maturation (Wyatt, 1980). These two factors have great implications for postharvest value, since pollination and seed production greatly contribute to floral senescence (Halevy and Mayak, 1981).

In the field, plants produce only one to a few stems (Lucansky and Clough, 1986; Wyatt, 1980) that arise from an erect perennial caudex located a few centimeters below the soil surface. Under moist, shaded conditions, stems will be longer than when growing in dry, sunny sites. The perennial caudex at the apical end of the woody taproot bears numerous adventitious buds. The caudex with buds is herein referred to as the crown.

Received for publication 20 Feb. 1990. Contribution no. 90-125-J of the Kansas Agricultural Experiment Station, Kansas State Univ., Manhattan, KS 66506. We wish to acknowledge The Fred C. Gloeckner Foundation for partial funding of this project. The cost of publishing this paper was defrayed in part by the payment of page charges. Under postal regulations, this paper therefore must be hereby marked advertisement solely to indicate this fact.
The greenhouse industry is constantly
The objective of this study was to determine the influence of daylength, cold storage, plant age, and planting depth on greenhouse forcing of greenhouse- and fieldproduced butterfly flower plants.

Cold- storage of 18-month-old, greenhouse-produced crowns grown in 15-cm (1.8liter) round, standard pots filled with a 1 soil :2 sphagnum peat : 2 perlite growing medium (by volume) amended with $3 \mathrm{~kg}$ dolomitic limestone $/ \mathrm{m}^{3}$ was initiated on 1 Oct. 1987. One-quarter of the dormant plants were maintained in a $10 \mathrm{C}$ greenhouse under natural daylength conditions and were moved remaining plants were held in a dark cold storage at $4 \mathrm{C}$ for 12,14 , or 16 weeks, with into the forcing greenhouse on $23 \mathrm{Dec}$. The one-third being placed in the forcing greenhouse on 23 Dec. 1987, 7 or 21 Jan. 1988, respectively. On each of these dates, plants were divided into three groups and forced under each of the following daylength conditions: 13-hr (black cloth pulled at 0800 and $1700 \mathrm{HR}$ and night interruption from 2200 to 0200 HR); 15-hr (black cloth pulled at 0800 and $1700 \mathrm{HR}$ and night interruption from 2100 to $0300 \mathrm{HR}$ ); or 17-hr (black cloth pulled at 0800 and $1700 \mathrm{HR}$ and night interruption from 2000 to 0400 HR). Forcing greenhouse growing temperatures were $17 / 25 \mathrm{C}$ night/day. Single plants served as an experimental unit in a $4 \times 3$ factorial arrangement in a randomized complete-block design with seven replications.

Field-produced, 6-month-old liners and 1year-old crowns were obtained from a commercial propagator in Michigan after they were dug from the field in early Mar. 1989. Upon arrival, liners were planted in $12-\mathrm{cm}$ (0.63-liter) round geranium pots, and 1-yearold crowns were planted in 15-cm (1.8-liter) round standard pots so the top of the caudex was exposed. A second group of liners and 1 -year-old crowns was planted in $18-\mathrm{cm}$ square $\times 28$-cm-deep containers so the top of the caudex was covered with $\approx 1.3 \mathrm{~cm}$ of medium. A 1 soil : 3 sphagnum peat : 3 perlite (by volume) growing medium, amended with $3 \mathrm{~kg}$ dolomitic limestone $/ \mathrm{m}^{3}$, was used. The plants were forced at 17/26C.

Plants were divided into three groups and forced under each of the following daylengths: 9-hr (black shade cloth pulled at 0800 and $1700 \mathrm{HR}$ ); 13-hr (black shade cloth pulled at 0800 and $1700 \mathrm{HR}$ and night interruption from 2200 to $0200 \mathrm{HR}$ ); and 17-hr (black shade cloth pulled at 0800 and $1700 \mathrm{HR}$ and night interruption from 2000 to $0400 \mathrm{HR}$ ). Natural daylengths at Manhattan, Kan. $\left(39.11^{\circ} \mathrm{N}^{\prime}\right.$ latitude) range from 9.4 to 14.9 hr. The daylengths chosen ensured that the plants would be exposed to true long-day (LD) and short-day (SD) conditions. Single
Table 1. Influence of cold storage period and daylength on the number of shoots and number of flowers per inflorescence present at market stage on greenhouse-produced, forced butterfly flower plants.

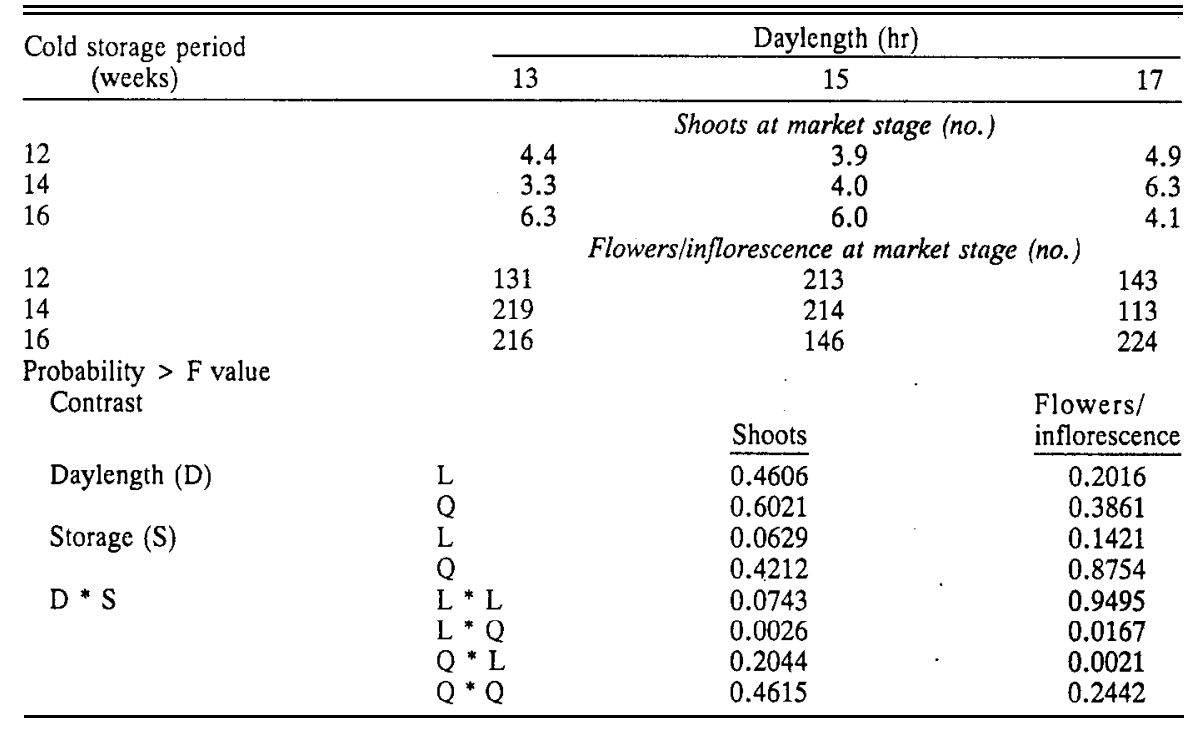


Table 2. Days required to reach market stage and number of flowers per inflorescence of greenhouse- vs. field-produced butterfly flower plants when greenhouse-forced.

\begin{tabular}{|c|c|c|}
\hline \multirow{2}{*}{$\begin{array}{l}\text { Plant } \\
\text { material }\end{array}$} & \multicolumn{2}{|c|}{ Daylength (hr) } \\
\hline & 13 & 17 \\
\hline & \multicolumn{2}{|c|}{$\begin{array}{c}\text { Interval to market } \\
\text { stage (days) }\end{array}$} \\
\hline Greenhouse-producedz & 71 & 61 \\
\hline \multicolumn{3}{|l|}{ Field-producedy } \\
\hline Liners & 81 & 96 \\
\hline Year-old crowns & 77 & 78 \\
\hline $\begin{array}{l}L_{S D_{0.0 s}}=9.8 \text { days } \\
\text { Field-produced pooled }\end{array}$ & 79 & $87^{*}$ \\
\hline & \multicolumn{2}{|c|}{$\begin{array}{c}\text { Flowers/inflores- } \\
\text { cence (no.) }\end{array}$} \\
\hline Greenhouse-produced ${ }^{\mathrm{z}}$ & 191 & 160 \\
\hline Field-producedy & & \\
\hline Liners & 96 & 81 \\
\hline Year-old crowns & 83 & 108 \\
\hline $\begin{array}{l}\mathrm{LSD}_{0.05}=26 \text { flowers } \\
\text { Field-produced pooled }\end{array}$ & 88 & $94^{\text {NS }}$ \\
\hline
\end{tabular}

${ }^{2}$ Forced in the 1987-88 growing season.

${ }^{y}$ Forced in the 1988-89 growing season.

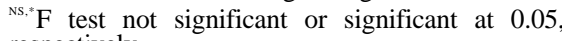
respectively.

plants served as an experimental unit in a 2 $\times 2 \times 3$ factorial arrangement in a randomized complete-block design with seven replications.

In both experiments, data were collected when the plants were at market stage, with $50 \%$ of the flowers per inflorescence having petals reflexed from the hood.

Greenhouse-produced plants stored in the 10C greenhouse never sprouted when moved to forcing temperatures. Plants held in cold storage for 12 or 14 weeks emerged in 16 days, whereas plants stored for 16 weeks sprouted in 9 days (contrast: linear $F$ value $=31.89, P>\mathrm{F}=0.0001 ;$ quadratic $\mathrm{F}$ value $=8.69, P>\mathrm{F}=0.0047)$. Prolonged cold storage also reduced the time to market stage from 70 days for plants stored 12 or 14 weeks to 56 days for those held 16 weeks at $4 \mathrm{C}$ (contrast: linear $\mathrm{F}$ value $=78.85, P$ $>\mathrm{F}=0.0001$; quadratic $\mathrm{F}$ value. $=25.93$, $P>\mathrm{F}=0.0001)$. The time to reach market stage also was reduced from 71 days to 64 days to 61 days when daylengths increased from 13 to 15 to $17 \mathrm{hr}$ (contrast: linear $\mathrm{F}$ value $=39,27, P>\mathrm{F}=0.0001$; quadratic $\mathrm{F}$ value $=0.76, P>\mathrm{F}=0.3857)$. There was no significant storage period-daylength interaction on the time to reach market stage. However, a significant interaction did occur for the number of flowers per inflorescence and the number of shoots on the plants at market stage (Table 1). The 17-hr daylength increased the number of flowers with an increase in storage.

The field-produced plants forced under the 9-hr daylength never flowered. There was a high percentage of flower bud abortion and shoot blindness. Bud abortion was defined as flower buds that turned brown and failed to develop once they had reached the visible bud stage. Shoot blindness was expressed as very small terminal leaves and no visible flower buds, resembling a blind rose shoot. Seventy-two percent of the shoots on fieldproduced liners forced under the 9-hr daylength were blind; $57 \%$ of the shoots on the 1-year-old crowns were blind. All remaining shoots showed aborted flowers.

Comparing the time to reach market stage for field-produced liners and 1-year-old crowns forced under 13- and 17-hr daylengths, there was a significant delay, relative to greenhouse-produced plants, for liners reaching market stage under the 17-hr daylength (Table 2). Field-produced liners were delayed in sprouting ( 49 vs. 39 days, $P>\mathrm{F}$ $=0.05)$ and required more time to reach the visible bud (66 vs. 55 days, $P>\mathrm{F}=0.02$ ) and market stages (88 vs. 77 days, $P>\mathrm{F}$ $=0.02$ ). There was no significant influence of the depth of planting the field-produced crowns on the number of shoots that sprouted, even though those that were planted with the crown below the medium surface had bettersupported stems.

Relative to greenhouse-produced plants, there was a reduction in the number of flowers per inflorescence when field-grown plants were forced (Table 2). The number of flowers per plant was similar to the flower counts reported for plants grown in natural habitats (Wilbur, 1976; Wyatt, 1980). Field conditions during the previous growing season might have had an influence on the initiation of floral primordia before the onset of dormancy. Soil and air moisture, which may be restricted under field conditions as compared to the greenhouse environment, might have been the contributing factors. Watson and Hanham (1976) showed a strong positive relationship of soil and air moisture with petal and hood size. It is highly probable that under reduced soil and air moisture conditions found in the field, fewer flowers are initiated in the butterfly flower meristem. It should be noted that the greenhouse-produced, greenhouse-forced plants had more flowering shoots at the market stage (Table 1) than the field-produced, greenhouse-forced plants (mean of 2.4 flowering stems per plant) and more than flowering plants in the field. Wilbur (1976) reported an average of 2.3 flowering stems per plant; Wyatt (1980) reported a range from 2.5 to 3.0 , depending upon site and growing season.

As daylength increased to $17 \mathrm{hr}$, greenhouse-produced butterfly plants required less time to reach market stage; field-produced butterfly plants showed a delay in reaching market stage. This delay may relate to the amount of low-temperature exposure the crowns received. The field-produced plants received the low temperatures in the field, whereas the greenhouse-produced plants were placed in walk-in cold storage units. Bernier (1988) explained that several LD plants have a substantial response to LD conditions only if the low-temperature treatment is sufficiently long. The field-produced liners, overwintered in the field, may not have received as much exposure to low temperatures and, thus, were not as responsive to LD exposure.

The field-produced liners also may have been in a transitional stage from juvenility to maturity, since the 1-year-old, field-produced crowns did not exhibit this delay to market stage. Lyons and Booze (1983) reported that seedlings did not bloom in the greenhouse under LD conditions using a 4$\mathrm{hr}$ night interruption or under natural SD conditions. Juvenility has been observed in Asclepias exaltata as well (Shannon and Wyatt, 1986). The lack of flowering in seedlings and the delay in flowering of the fieldproduced liners suggest a strong juvenile growth phase in butterfly flower.

Greenhouse-produced butterfly plants will have more flowers and flowering shoots than field-produced plants, thereby producing a more attractive potted plant than field-produced, greenhouse-forced plants. Daylength has an influence on flowering.

\section{Literature Cited}

Bernier, G. 1988. The control of floral evocation and morphogenesis. Annu. Rev. Plant Physiol. Plant Mol. Biol. 39:175-219.

Halevy, A.H. and S. Mayak. 1981. Senescence and postharvest physiology of cut flowers, part 2. Hort. Rev. 3:59-143.

Lucansky, T.W. and K.T. Clough. 1986. Comparative anatomy and morphology of Asclepias perennis and Asclepias tuberosa subspecies Rolfsii. Bet. Gaz. 147(3):290-301.

Lyons, R.E. and J.N. Booze. 1983. Effects of photoperiod on first-year growth of 2 Asclepias species. HortScience 18(4):575. (Abstr.)

Shannon, T.R. and R. Wyatt. 1986. Reproductive biology of Asclepias exaltata. Amer. J. Bet. 73(1)\%-20.

Watson, L.J. and R.Q. Hanham. 1976. Environment and the morphological characteristics of butterfly weed in Oklahoma. J. Biogeography 3:383-388.

Wilbur, H.M. 1976. Life history evolution in seven milkweeds of the genus Asclepias. J. Ecol. 64:223-240

Wyatt, R. 1980. The reproductive biology of Asclepias tuberosa: I. Flower number, arrangement, and fruit-set. New Phytol. 85:119-131.

Wyatt, R. 1981. The reproductive biology of Asclepias tuberosa: II. Factors determining fruitset. New Phytol. 88:375-385. 